\title{
Female Urethral Disease: A Contemporary Review of Presentation, Diagnosis and Current Management Strategies
}

\author{
Zebulun Cope ${ }^{1, *}$, Christopher Anglin², Arrionna Dryden³, Jenci Hawthorne ${ }^{2}$, and Kellen Bo Yung Choi ${ }^{4}$ \\ ${ }^{1}$ Department of OBGYN, Division of FPMRS, University of Louisville School of Medicine, Louisville, KY, USA \\ ${ }^{2}$ University of Louisville School of Medicine, Louisville, KY, USA \\ ${ }^{3}$ Michigan State University School of Medicine, Grand Rapids, MI, USA \\ ${ }^{4}$ Department of Urology, University of Louisville School of Medicine, Louisville, KY, USA
}

*Corresponding author: Zebulun Cope, Department of OBGYN, Division of FPMRS, University of Louisville School of Medicine, 550 South Jackson St, Louisville, KY, USA 40202, E-mail: Dr.ZebCope@Outlook.com

Received: 09 Oct, 2020 | Accepted: 31 Oct, 2020 | Published: 06 Nov, 2020

Citation: Cope Z, Anglin C, Dryden A, Hawthorne J, Choi KBY (2020) Female Urethral Disease: A Contemporary Review of Presentation, Diagnosis and Current Management Strategies. J Surg Open Access 7(1): dx.doi.org/10.16966/2470-0991.228

Copyright: (c) 2020 Cope Z, et al. This is an open-access article distributed under the terms of the Creative Commons Attribution License, which permits unrestricted use, distribution, and reproduction in any medium, provided the original author and source are credited.

\section{Abstract}

Background: Female urethral diseases are sparsely discussed within the literature when compared to urethral diseases affecting men. While, the male urethra is impacted more frequently secondary to the comparative increase in average length, presence of the prostate and considerations of carrying genetic material-disease process of the female urethra impose significant distress to affected patients and also potential for malignancy. The clinical presentation and management strategies often differs from the male counterpart and therefore it is important to consider disease processes of the female urethra unto their own right for evaluation and successful management. It is to that end this publication is put forth.

Methods: A contemporary review of the current thoughts regarding clinical presentation, diagnosis, and management strategies; both conservative and surgical, are presented for female acute urethritis, atrophic urethritis, urethral pain syndrome, urethral caruncle, urethral prolapse, urethral diverticulum, urethral stricture disease, and primary urethral carcinoma/primary urethral melanoma.

Conclusions: Female Urethral Disease is a unique entity apart from the male counterpart and the clinical presentation, incidence, prevalence and management strategies are distinct for many of the disease processes discussed. Often a high index of suspicion is needed to arrive at a timely, correct diagnosis. It is imperative that clinicians and surgeons consider this point to reduce the duration of distress, number of practitioners the average woman contending with these disease processes must see and the possible undesired sequalae if a disease process remains untreated and worsens or malignancy progresses.

\section{Introduction}

Disease processes of the urethra, whether benign or malignant, are predominantly discussed in both terms of clinical presentation and management as they pertain to male patients. Given that the average length of the male urethra is 4-5 times the length of the average female's, $18-20$ centimeters $(\mathrm{cm})$ and 3-4 $\mathrm{cm}$ respectively, the presence and pathology associated with the male prostate and the additional function of the male urethra of delivering genetic material the predominance of literature regarding male urethral disease opposed to female urethral disease is somewhat understood. However, female urethral diseases whether benign or malignant often have a clinical presentation, etiology and management distinct from their male counterparts. The decreased prevalence of urethral diseases in women and distinct presentation of pathology can result in delayed diagnosis and sub-optimal treatment processes.

It is to that end we present a contemporary review of the most common benign and malignant female urethral diseases with discussions of the clinical presentation, most current diagnostic modalities and treatment methods.

\section{Acute Urethritis}

Acute urethritis, is defined as inflammation of the urethra and presents secondary to the most common etiology of infections, such as Urinary Tract Infections (UTIs) and Sexually Transmitted Infections (STIs), or noninfectious etiologies such as chemical urethritis and trauma [1-3]. Acute urethritis is one of the most common presenting diagnoses in women with a reported overall incidence of more than 4 million American men and women each year [3-5]. Risk factors for acute infectious urethritis secondary to STIs are young age (less than 25 years of age), unprotected sexual intercourse, multiple sexual partners and UTIs $[3,5,6]$. Risk factors for an UTI infectious etiology include postmenopausal status/hypoestrogenic state/vulvovaginal atrophy, history of recurrent UTIs female sex, frequent intercourse and use of certain birth controls (diaphragms and spermicidal agents) $[7,8]$. Additionally, women with underlying medical conditions 
such as diabetes mellitus, immunocompromised states, or history of urologic conditions that include but are not limited to neurogenic bladder, indwelling catheters, and renal transplants, have increased risk of developing acute urethritis, whether of infectious or noninfectious etiologies, and ultimately more severe sequalae [9]. Urethral trauma, instrumentation, and increased number of pathogenic infections often leads to and can ultimately progress through the lower urinary tract to cause cystitis and/or pyelonephritis [10].

Urethritis caused by STIs is often discussed as either gonococcal, with an etiology of Neisseria gonorrhea being the causative agent, or Nongonococcal Urethritis (NGU) [11-13]. Gonorrhea is the second most commonly reportable disease in the United States with 583,405 cases reported in 2018 for a rate of 179.1 cases per 100,000 population [12]. Chlamydia is the most common notifiable disease in the United States, the most common NGU cause of urethritis and among the most prevalent of all STIs comprising the largest proportion of STIs reported to the CDC. In 2018, 1,758,668 chlamydial infections were reported to the CDC in 50 states and the District of Columbia corresponding to a rate of 549.9 cases per 100,000 population and comprising between $15-40 \%$ of all NGU cases as a whole $[3,13,14]$. The second most common cause of NGU is the fastidious Mycoplasma genitalium accounting for $15-20 \%$ of cases and is not uncommonly found contributing to a co-infection with Chlamydia [3,14]. Less common causes include Trichomonas vaginalis, herpes simplex virus, Epstein Barr virus, Candida, Hemophilus influenzae, Treponema pallidum and Adenovirus [3,14]. Despite the breadth of contributory pathogens of NGU the causative etiology remains unidentified in nearly half of all cases [14]. Although acute urethritis secondary to STIs is exceedingly prevalent, it is rare for urethral infections to occur without concomitant cervical involvement due to source of infection $[15,16]$. Given the high prevalence of both Gonococcal and NGU pathogens involved in acute urethritis, challenges may present when attempting to differentiate between the two. Treatment of STI urethritis is important in women as untreated or inadequately treated sequalae may result in Pelvic Inflammatory Disease (PID) which carries its own potential for long term side effects of tubal infertility, ectopic pregnancy, and chronic pelvic pain [12,14]. Additionally, beyond PID sequalae of conjunctivitis and Reactive Arthritis; formerly known as Reiter Syndrome and characterized by sterile synovitis occurring in a genetically predisposed individual secondary to a bacterial infection localized in a distant organ/system and in relevance to this publication often finds gonorrhea and chlamydia as etiologies, may occur [17]. Infections during pregnancy bear the risk of transmission to infants where ophthalmia neonatorum may occur which may lead to blindness and/or pneumonia in newborns [13].

Urethritis caused by UTIs has a spectrum of presenting symptoms from asymptomatic bacteriuria to pyelonephritis and can be difficult to diagnose with an estimated 150 million patients yearly resulting in at least $\$ 6$ billion in health care costs [18]. The pathogen most commonly involved in UTIs is $E$. coli with additional uropathogens including Klebsiella, Proteus, Enterobacter spp. and enterococci [19-21]. As the female distal urethra has multiple potential pathogens that can lead to acute and subsequently chronic urethritis, the female urethra also provides a favorable environment for colonization by uropathogens although it is inherently protected by defense mechanisms [22,23]. Examples of these defense mechanisms are seen with shedding of uropathogens bound to urethral cells, where mucus secreted by paraurethral glands ultimately traps bacteria, washout urine removes the pathogen from the urethra and local production of antibodies, cytokines and other immunological cells contribute to disposing of pathogens as well $[24,25]$.
In addition to infectious causes of urethritis, chemicals can lead to a subset of acute urethritis known as chemical urethritis. Chemical urethritis is caused by foreign substances coming into contact with the urethra, which includes various hygiene substances such as soaps, lotions, laundry detergents, and some spermicidal jellies [26]. These chemical irritants tend to predominantly affect young women and present in a similar fashion to pathogenic urethritis, making it essential to address changes and use of hygiene products and practices on interview.

\section{Clinical presentation}

Many women with STIs may be asymptomatic upon presentation; thus the reasoning behind the current screening recommendations from the Center for Disease Control to have women younger than 25 years old screened annually for Chlamydia and Gonorrhea [12-14,27]. Women with symptoms of acute urethritis secondary to a STI often present with concomitant symptoms of vaginitis as well. Symptomatic women may present with dysuria, urinary frequency, cervicovaginal irritation abnormal purulent, mucoid or watery vaginal discharge, regional lymphadenopathy, intermenstrual; mainly postcoital, bleeding, and/or constitutional symptoms [13,14,28].

Women presenting with acute urethritis secondary to UTIs or chemical urethritis, predominantly demonstrate urinary symptoms, which can include urinary frequency, urgency, mild to moderate dysuria with a form of discharge that can vary in presentation ranging from clear and white to mucoid to purulent $[7,8,14]$. Although uncommon, patients may present with general symptoms such as fever, chills, or myalgias which may be a sign of further complications such as pyelonephritis [29].

\section{Diagnosis}

Urethritis as a formal diagnosis was initially defined in males by: 1) Mucoid, mucopurulent or purulent urethral discharge on examination 2) Gram stain of urethral secretions demonstrating equal to 2 White Blood Cells (WBC) per oil immersion field or 3) Positive leukocyte esterase test on urinalysis or microscopic examination of sediment from a spun first-void urine demonstrating equal to $10 \mathrm{WBC}$ per high power field [14,30].

As acute urethritis may often present with the signs and symptoms of vulvovaginal itching, burning, irritation, dyspareunia, abnormal vaginal odor and/or discharge which is consistent with the clinical presentation of vaginitis; clinical evaluation may initially follow to the most common causes of vaginitis. The evaluation for vaginitis is most notably concerned with evaluating for the presence of Bacterial Vaginosis (BV), Trichomoniasis and/or vulvovaginal candidiasis with each being detected as the causative factor in up to $50 \%, 35 \%$ and $39 \%$ respectively for cases of vaginitis [31]. A complete medical history is collected with a focus noting menopausal status, sexual practices and recency of any sexual practices and prior episodes of the aforementioned diagnosis. A physical exam of the vulva and vagina with clinical testing of vaginal discharge via vaginal $\mathrm{pH}$ testing, a $10 \%$ Potassium Hydroxide $[\mathrm{KOH}]$ "whiff" test and $0.9 \%$ saline microscopy should follow [31]. The normal $\mathrm{pH}$ of the vagina is between 3.5-4.5, produces a negative "whiff" test, where a positive test is noted by an amine or fishy odor when $\mathrm{KOH}$ is added to vaginal discharge, with saline microscopy revealing rare Polymorphonuclear Leukocytes (PMNs), a predominance of lactobacillus and mature squamous cells. A vaginal $\mathrm{pH}$ that is more basic than normal raises the possibility of BV and/or Trichomoniasis higher on the differential. Diagnosis of BV clinically often follows the Amsel criteria with 3 out of the following 4 elements being required for diagnosis: 1) Homogenous, thin, 
white-gray vaginal discharge 2) More than 20\% vaginal squamous cells studded with coccobacilli ("Clue cells") on saline microscopy 3) Vaginal pH greater than 4.5 and 4) Positive "whiff" test on application of $\mathrm{KOH}$. Gram stain with Nugent scoring is the reference standard for diagnosis of BV; however, its use secondary to practicality is often reserved more for research purposes. Trichomoniasis often presents with a yellow to green frothy vaginal discharge and pruritus with both an abundance of trichomonads and PMNs on saline microscopy. It is not uncommon for Trichomoniasis to have a positive "whiff" test. Despite the possibility of findings via saline microscopy and $\mathrm{KOH}$ application the preferred diagnostic test for Trichomoniasis is via vaginal swab followed by NAAT as will be further explained below. Vulvovaginal candidiasis often has a clinical presentation that involves thick, white, "curd" like vaginal discharge with a normal vaginal $\mathrm{pH}$ and presence of rare PMNs mature squamous cells on saline microscopy and branching pseudohyphae and/or spores being visualized after application of $10 \% \mathrm{KOH}$ [31]

It is important to consider that any presentation may have a polymicrobial etiology therefore when history and physical presentation point to the possibility of a STI as the etiology of signs and symptoms a complete evaluation should include the preferred screening method which is a cervicovaginal swab that will be sent for Nucleic Acid Amplification Tests (NAAT) and possible culture [27]. A cervical swab may be obtained if examination is occurring during a pap smear as the cervical swab has comparable sensitivity and specificity of detection to a vaginal swab [6]. Patients may administer a "self" vaginal swab for collection as identification of infection via that method proves to be equivalent in sensitivity and specificity to collections done by a clinician [32-34]. And although, first catch or "dirty catch" urine specimens are acceptable for screening such screening may detect up to $10 \%$ fewer infections compared to vaginal or endocervical swab samples [32]. Historically, cultures of urethral discharge from men have been used to establish the diagnosis of urethritis with the presence of diplococci, indicating $N$. gonorrhea, on gram strain demonstrating a diagnosis of gonococcal opposed to non-gonococcal urethritis. However, NAATs have become first line for establishing a diagnosis of acute urethritis in today's clinic [32]. Until the introduction of NAATs, which detects and amplifies pathogen RNA or DNA opposed to detecting the presence of antigens or antibodies, cell culture was the most sensitive diagnostic test. However, given the relative difficulties in standardization, relatively high cost and transport requirements NAAT superseded specimen culture for the preferred test [32]. Additionally, non-viable pathogens can be detected via NAAT, which increase flexibility for transport and accuracy of samples $[35,36]$. Screening for $N$. gonorrhoeae may occur via NAAT swab as discussed above or via urethral, if discharge is present, or cervicovaginal culture with Thayer-Martin medium to induce growth of the pathogen if present. And while NAAT is sufficient to detect the presence of gonorrhea a culture allows the ability to further characterize the isolate by antimicrobial susceptibility testing and genetic analysis if necessary which may become important if faced with treatment failure [32].

The evaluation of acute urethritis suspected secondary to an UTI begins with a collection of a urine sample. Urine samples for UTI evaluation are collected via 3 main collection methods: 1) via a "clean" catch, midstream, collected urine sample 2) catharized urine or 3) urine aspirated suprapubically [37]. The analysis of the urine that follows often occurs in a somewhat stepwise fashion beginning with urinalysis. Most clinics perform initial chemical urine analysis with a "dipstick" as it is relatively quick, requiring often between 2-30 minutes, can be associated with up to $99 \%$ specificity and $91 \%$ sensitivity on diagnosing UTI in a symptomatic patient. The urinalysis dipstick test most notably evaluates for 2 main components: 1) Nitrites (which is indicative of the presence of gram negative bacteria, which are often the etiology of UTIs, converting nitrates to nitrites in the urine and 2) Leukocyte esterase, which is an enzyme produced by White Blood Cells (WBCs) and is indicative of their presence in urine. Urine microscopy may follow as an adjunct. Urine microscopy detects the actual presence of WBCs in urine (pyuria). Pyuria is the most reliable indicator of infection and is often defined as (>10 WBC/ hpf on a spun specimen) and is $95 \%$ sensitive [37]. Additionally, the potential for a contaminated specimen is evaluated by the quantitative presence or absence of squamous epithelial cells (depending on lab specifications). Hematuria is also detected and as a "reflexive" urine culture often follows a positive UA and or urine microscopy a negative urine culture with the presence of hematuria, gross or microscopic, often indicates a full evaluation for hematuria should be performed. The third main component to diagnosis a UTI is a quantitative urine culture. In general, the presence of more than 100,000 colony forming units/mL of no more than two uropathogens is diagnostic for a UTI. The quantitative value indicating infection may be lower if the collected specimen was obtained via sterile catherization or suprapubically [37]. A full evaluation of UTI should also include a physical exam to assess for upward mobility of infection to the kidneys, This evaluation occurs via assessing costovertebral angle tenderness (Lloyd's sign) demonstrated during CVA palpation (Lloyd's punch) is essential to prevent serious illness and determine severity of disease [38].

\section{Management}

Treatment for symptoms of acute female urethritis is directed towards the etiology and resolution is often achieved with antimicrobial drugs [39]. Historically treatment of urethritis has brought debates among physicians regarding different antibiotic use. Management of chemical urethritis, as it is often secondary to an environmental irritant, is often accomplished via a trial and error process where different items whether detergents, certain fabrics on underwear, soaps, etc., are sequentially removed and/or re-added [40]. For UTIs, first line treatment includes cephalexin, or trimethoprimsulfamethoxazole for 3-5 days.

For uncomplicated gonococcal urethritis, the CDC recommends treatment with a cephalosporin, a single doses of 250 milligram intramuscular ceftriaxone, and 1 gram of oral azithromycin as first line therapy [41]. Preferably, the two antibiotics should be administered simultaneously and under direct observation [41,42]. Given the challenges with culturing both gonorrhea and chlamydia, NAAT is of utmost importance but still leaves the door open for possible coinfection, especially when chlamydia is negative on NAAT urine testing.

For NGU management-namely chlamydia, a single 1 gram dose of azithromycin is as effective for the treatment of uncomplicated genital chlamydial infections as a standard seven-day course of doxycycline, leading to increased compliance with treatment and reducing recurrence of acute urethritis $[43,44]$. Azithromycin or doxycycline is also effective in treating urethritis caused by U. urealyticum. Given the prevalence of Trichomonas vaginalis and Mycoplasma genitalium in women, there have been studies to assess whether anti-trichomonal treatment with azithromycin or doxycycline would also be effective at treating those pathogens with the aim of increasing cure rates for acute urethritis. To date, no randomized controlled trial has demonstrated effective anti-trichimonal via those antibiotics [45].

Patients should be re-evaluated after antibiotic therapy, with the CDC recommending performing a test of cure 2 weeks after treatment, 
if symptoms persist as there may be underlying inflammation of the urethra, signs of chronic urethritis or untreated sexual partners [44]. Of particular ethical and legal interest for recurrent urethritis is partner treatment, commonly referred to as Patient-Delivered Partner Therapy or Expedited Partner Therapy (EPT), which is the simultaneous cotreatment of a partner to enhance the chances of success of therapy without necessarily assessing the partner in the clinic [46]. The Center for Disease Control, the American College of Obstetricians and Gynecologists, and American Academy of Family Physicians, American Academy of Pediatrics, American Medical Association, and Society for Adolescent Health and Medicine support EPT for gonococcal and chlamydial infections, although state laws vary [5]. Based on the CDC as of September 21, 2020, EPT is permissible in 45 states, potentially allowable in 4 states, including Alabama, Kansas, Oklahoma, and South Dakota, and prohibited in South Carolina [47]. These ethical and legal realms of knowledge are essential when considering acute versus chronic urethritis in female patients.

\section{Atrophic Urethritis}

In 2014, the International Society for the Study of Women's Sexual Health and the North American Menopause Society defined symptoms such as vulvovaginal and urethral atrophy as part of the constellation of symptoms associated with the postmenopausal hypoestrogenic state as Genitourinary Syndrome of Menopause (GSM). It is defined as "a collection of signs and symptoms associated with a decrease in estrogen and other sex steroids involving changes to the labia majora/minora, clitoris, vestibule/introitus, vagina, urethra and bladder" [48]. Atrophic urethritis, therefore, can be defined as the thinning of urethral and vulvar tissue secondary to hypoestrogenic changes. It is most commonly seen with surgical menopausal and postmenopausal women but can also occur in premenopausal women with diminished estrogen production. As the vaginal vestibule, lower fifth of the vagina, urinary bladder, trigone and entire urethra are derived from the urogenital sinus, Mullerian ducts and sinovaginal node embryologically and share common estrogen receptor functions a hypoestrogenic state tends to have similar effects on all these tissues [49]. Stimulation of those estrogen receptors is responsible for maintaining collagen content of the epithelium, moisture of the epithelial surfaces, and overall blood flow of those tissues during reproductive years [50]. As a direct result of decreased estrogenic stimulation, the urethra becomes thin, dry, and susceptible to trauma, predisposing patients to tissue inflammation, recurrent urinary tract infections, dysuria and chronic pain.

The differential diagnosis for atrophic urethritis, and other symptoms related to GSM, include all other causes or urogenital discomfort, and therefore, must be carefully ruled out with a thorough history and pelvic examination [48, 50,51]. Those affected by 1 or more symptoms of GSM are estimated to be between $10-40 \%$ of postmenopausal women and up to $15 \%$ of premenopausal women; however, this number is thought to be largely underreported likely secondary to patient discomfort in discussing symptoms and/or underdiagnosis $[49,51,52]$. The subset of women that would then report/be diagnosed with atrophic urethritis would fall within those estimates and also be subject to the likely underreporting.

\section{Clinical presentation}

The clinical presentation of atrophic urethritis may include, but is not limited to, patient concerns of urinary frequency, urgency, nocturia, dysuria/periurethral discomfort (especially during intercourse), stress incontinence of various severities, recurrent UTIs and even hematuria $[49,51,53]$. Atrophic urethritis is often not seen in isolation; more so, as previously mentioned it tends to be an additional or under arching finding within GSM. Dysuria, therefore may be secondary to urine coming into contact with inflamed atrophic paravaginal tissue and/ or a sign of UTIs in this subset of women [51]. There is an established link between the decrease in acid-generating bacteria, decrease of the vaginal microbiome and increase in coliform species within the vagina that is attributed to the hypoestrogenic postmenopausal state and the reported 5\%-17\% of postmenopausal women who have recurrent UTIs $[51,53,54]$.

On physical exam, the vaginal tissue may appear excessively dry, thin, pale and shiny with decreased rugation lacking elasticity and with possible friable tissue with patients reporting irritation/burning with light palpation $[54,55]$. In the hypoestrogenic state the urethra may reveal an erythematous appearance with small petechiae or ecchymoses near the periurethral tissue. The observation of a urethral caruncle and/or urethral meatal eversion secondary to different degrees of urethral prolapse may accompany or present in isolation to the physical finding of circular banding just below the urethra [54].

\section{Diagnosis}

The diagnosis of atrophic urethritis can be made clinically from symptoms reported on history and characteristic signs during physical exam. Although, the initial diagnosis is presumptive from the state of being postmenopausal/hypoestrogenic with relevant signs and symptoms that usually instigate the first lines of treatment, which are discussed below, failure of initial therapy may necessitate further evaluation. The full history that is relevant to atrophic urethritis/ GSM should include an account of lubricants, spermicides, powders, soaps and panty liners used as periurethral/vaginal irritation may be the cause of the discomfort $[49,51]$. Medical/Surgical history should account for history of oophorectomy, radiation and or chemotherapy which can all induce hypoestrogenic states $[49,56]$. As the differential diagnosis may include infectious etiologies such as BV, candidiasis and trichomoniasis, among others, either in isolation or concomitant to the hypoestrogenic state cytologic evaluation via microscopy and/ or wet mount of the vaginal/periurethral tissue may be helpful in planning successful treatment. The presence of an increased number of parabasal cells with a decrease of superficial cells on microscopy is indicative of a hypoestrogenic state [49,56]. Histological evaluation of the tissues may aid in diagnosing lichen sclerosis and/or lichen planus when suspicion arises $[49,57]$. Assessment of the vaginal $\mathrm{pH}$ typically reveals a more basic $\mathrm{pH}$ above the normal 3.5-4.5 making the urethra more susceptible to UTIs that typically are seen along with GSM [49]. Assuring that pap smears with or without colposcopy/vaginoscopy are up to date as relevant and consideration of Ultrasound, MRI and/ or CT when suspicion of vaginocervical cancer presents either with unresolved symptoms or new suspicious findings should also always be of consideration [49]. When concern of cancer is found more isolation to the urethra urine cytology and cystourethroscopy with or without biopsy is helpful at definitive diagnosis (see Primary Urethral Cancer below) $[58,59]$.

\section{Management}

Local vaginal estradiol and local conjugated equine estrone whether as a cream, within a ring or tablet form have all proven effective at managing GSM and the extended subset of urethral atrophy $[51,60]$. Concerns over the minimal systemic absorption of the hormone causing endometrial hyperplasia have been unsubstantiated in a recent Cochrane review [61]. However, the alleviation of concern has not been extended to women with a history of breast cancer as long-term data at current is unavailable [51]. 
Ospemifene and dehydroepiandrosterone are non-hormonal treatment options that are used to treat some element of GSM [51]. Ospemifene is an estrogen agonist/antagonist that has been found to improve vaginal tissue atrophy without stimulating the endometrium [51]. While initially FDA approved for moderate to severe dyspareunia in postmenopausal women in 2013 the indications for use were expanded to use for moderate to severe vaginal dryness due to menopause in 2019 [52,62]. Dihydroepiandrosterone or vaginal Prasterone increases baseline estrone through aromatization and has FDA indications for dyspareunia in menopausal women [63]. With alterations in moisture and tissue thickness of vaginal and paravaginal tissue the symptom relief of the urethra can be extrapolated from the vaginal alterations.

"Vaginal rejuvenation," presented most frequently via two main energy based platforms laser and radiofrequency, purports to provide an option to treat GSM in women who are unable to utilize hormonal therapy [52]. However, the FDA currently maintains that these methods pose serious risks of harm to patients without adequate evidence of benefit [64]. Nevertheless, some plastic surgeons, dermatologists and gynecologists offer the umbrella term of "vaginal rejuvenation" for patients with atrophic vaginal and paravaginal tissue throughout the country [52].

Treatment with the aforementioned FDA approved methods that does not resolve symptoms of urethral atrophy should be further investigated with possible surgical management that may follow either treatment of urethral strictures and/or primary urethral cancer (See Primary Urethral Carcinoma \& Urethral Stricture Sections below).

\section{Urethral Pain Syndrome}

Urethral Pain Syndrome (UPS) or Urethral Syndrome is a diagnosis of exclusion that has been defined by the International Continence Society as "the occurrence of recurrent episodic urethral pain usually on voiding, with daytime frequency and nocturia, in the absence of proven infection or other obvious pathology" [65]. There is an element of chronicity to the disorder with 6 months being the usual minimal duration of symptoms. Often, women have initiated their treatment with primary care physicians where their initial concerns of dysuria with or without frequency/urgency present a clinical picture of a urinary tract infection. This presentation is often coupled with the temporary symptomatic relief following a course of antibiotics; however, return of the bothersome symptoms soon follows [66].

The exact incidence and prevalence of this disease is difficult to ascertain secondary to historical variations of its definition. In one study the incidence was quoted to be approximately $15 \%$ of the premenopausal population while another publication remarked that it resulted in nearly 5 million clinic visits per year in the United States $[67,68]$. The condition does appear to be more prevalent in Caucasian women and to have a bimodal distribution of those affected with most patients that are affected either being in the 20-30 age range or 50-60 years of age [66]. Proposed etiologies have been urethral stenosis, presence of fastidious organisms such as Mycoplasma hominis, Ureaplasma urealyticum and Chlamydia trachomatis, an early manifestation of Painful Bladder Syndrome, hypersensitive neuropathic pain following a UTI and stress [66]. A more recent hypothesis gaining traction as the source of symptoms is the concept of bladder and urethral mucosa presenting with a dysfunction resulting in an abnormal movement of solutes across the mucosa. The most notable urinary metabolite implicated as a source of discomfort as it reaches the underlying muscle layer is potassium-injuries in the mucosal layer of the urethra and bladder have demonstrated this abnormal movement both in vitro and in vivo with both rodents and humans [68]. As Urethral Pain Syndrome is part of an overarching category of somatic symptom disorders it shares the propensity towards patients who suffer from it showing signs of psychological distress most notably by way of stress and anxiety as the disease has demonstrated a negative effect on quality of life [69].

\section{Clinical presentation}

The clinical presentation follows the persistence of the chief concerns of the patient of dysuria, urinary frequency and/or urgency with or without short term relief from a course of antibiotics and absence of explanatory findings from other diagnostic test. Those largely or wholly unremarkable tests may include physical exam, cystoscopy, urine analysis/culture, urethral/vaginal/endocervical swabs and imaging which may include ultrasound, intravenous urography and/ or MRI [66,70].

\section{Diagnosis}

The diagnosis follows in the absence of findings in the evaluation while the chronicity of symptoms persists; i.e. it is a diagnosis of exclusion. Additional to the aforementioned testing in the prior section-a urodynamic study may often be performed secondary to the patient reports of frequency and urgency in order to rule out detrusor over activity and detrusor-sphincter-dyssynergia. Urethral pressures profile my reveal relative degrees of urethral instability.

\section{Management}

Following the management of other chronic somatic symptom disorders the approach to symptom relief is best approached multimodally with the favorable results reached via "trial-and-error" $[66,70]$. While therapy incorporating one or some elements of alpha-blockers, topical estrogen/corticosteroids, anesthetics/mucosal protecting agents, physical therapy with or without bladder training and urethral dilation all appear to be more universally accepted as a part of the management regimen direct controversy exists over the use of antibiotics for the treatment of UPS. Some practitioners advocate for initial therapeutic use, prophylactic use or no use of antibiotics at all unless urinary culture indicates presence of an infectious etiology [66,70-72]. Reports of Complementary Alternative Medical (CAM) therapy in the way of acupuncture and electo-acupuncture have shown to provide symptom relief in a randomized control trial [73]. While there have been reports of use of Onabotulinumtoxin A injections into the urethra-the indications for that procedure related more to neurogenic bladder and detrusor-sphincter dyssynergia rather than to UPS [74].

Topical therapy to the urethra with clobetasol propionate mixed with lidocaine has been described with great results in regards to symptom reduction with the added benefit of minimal side-effects [72]. Antimuscarinic therapy is thought to be effective secondary to its overall reduction of bladder muscle contractility which may relieve symptoms at the urethra [66]. In a more direct management of the urethra Alpha-blocking agents decrease tone at the bladder neck and urethra directly resulting in relief $[66,75]$. Tricyclic antidepressants, most notably Amitriptyline, have been utilized with success in other somatic pain disorders such as fibromyalgia, irritable bowel syndrome and interstitial cystitis along with favorable management of UPS [76]. Typically, the maximum duration of use is approximately 3 years. A more recent paper describes symptom relief with the use of sertraline and gabapentin; however, the entire cohort for this study was male [69].

Surgical correction for UPS centers largely around urethral dilation. However, the etiology for UPS in that case especially if symptom relief 
is accomplished presents itself as a diagnosis of urethral stenosis [66]. In an attempt to restore the dysfunctional urethral mucosa to a less irritative/symptomatic state laser therapy has been proposed as a treatment modality with at least one randomized trial showing both symptom relief and durability to its results [77].

\section{Urethral Caruncle}

A urethral caruncle is a benign tumor of the distal urethra that usually occurs at the posterior lip of the urethral meatus. It is the most common benign tumor of the female urethra, typically seen in postmenopausal women, however, there are documented cases that have occurred in younger patients [78,79]. The etiology of urethral caruncles is poorly understood. It is thought to be due to a hypoestrogenic state, most often estrogen deficiency secondary to menopause that results in uroepithelial atrophy and predisposes the urethral mucosa to prolapse. Subsequent exposure to clothing and a less inherently moist environment of the prolapsed tissue is thought to lead to inflammation, bleeding, and necrosis [80]. Other suggested etiologies include urethral congestion, chronic irritation, and trauma [81]. While there are case reports of malignancies mimicking urethral caruncle there are no documented primary cancers associated with urethral caruncle [82-84]. Additionally, there are no documented associations with systemic diseases or other urologic disorders [85].

Histologically, these lesions are composed of variable proportions of fibrosis, subepithelial inflammation, edema, vascularity, and epithelial hyperplasia, which may mimic a neoplasm [86]. The clinical differential diagnosis includes a wide variety of both benign and malignant conditions, including urethral diverticulum, urethral polyp, periurethral gland abscess, squamous intraepithelial neoplasm, carcinoma, and melanoma [87-89]. Because of this, pathologic confirmation is of utmost importance.

\section{Clinical presentation}

Patients with urethral caruncle typically present with pain, hematuria, and/or dysuria [90]. Other symptoms that can occur include postmenopausal bleeding, urinary incontinence, and in isolated cases, urinary retention $[91,92]$. Patients may also be asymptomatic. One study, in particular, found that $32 \%$ patients with caruncles were asymptomatic $[10,93]$.

The lesion itself is usually a soft, pink/red, sessile or pedunculated polypoid nodule that protrudes from the urethral meatus [94]. They are often easily friable and can also be ulcerated, hemorrhagic, or velvety [85]. Caruncles are usually $1-2 \mathrm{~cm}$ in greatest dimension [93].

\section{Diagnosis}

The diagnosis of urethral caruncle can be made clinically. Initial workup should include a thorough physical exam of both the lesion and urethra to assess for additional, non-visible lesions or induration, which may suggest malignancy. If such abnormalities are noted, a cystourethroscopy may be indicated. Initial workup should also include a urinalysis and a urine culture if patients are found to have dysuria or hematuria. Although biopsy is not needed to diagnose urethral caruncle, excisional biopsy is indicated if the patient has any symptoms that resemble malignancy such as an irregularity, induration, local extension, lymphadenopathy, or increasing size.

\section{Management}

Asymptomatic lesions that are typical in appearance do not usually require treatment [92]. Initial management of symptomatic lesions involves topical estrogen cream, sitz-baths, topical antiinflammatories, or steroids [95]. If symptoms do not resolve or if the caruncle is particularly large and bothersome, biopsy with surgical excision is commonly performed [96]. Alternate treatment methods including ligation, cryotherapy, laser therapy, or fulguration have also been described $[92,97]$. Unfortunately, there are no large studies or randomized trials comparing different treatment strategies or assessing reliable recurrence rates for urethral caruncles [96].

\section{Urethral Prolapse}

Urethral Prolapse (UP) is a rare, benign condition described as eversion of the urethral mucosa through the external urethral meatus. It largely affects the premenarchal population with a greater propensity towards black girls although the disease can also be seen in the postmenarchial state as well [98]. The etiology has been hypothesized to originate with a poor attachment between the smooth muscle layers of the urethra that result in formation of a cleavage plane between the inner longitudinal and outer circular-oblique smooth muscle layers of the urethra predominately during periods of increased intraabdominal pressure [99]. Additionally, a number of case reports have implicated the use of urethral bulking agents utilized for the treatment of Stress Urinary Incontinence and/or Intrinsic Sphincter Deficiency as the inciting event [100-102]. As the differential diagnosis for this periurethral mass in children includes urethral caruncle, congenital prolapsed ureterocele and sarcoma botryoides timely confirmation of the diagnosis is paramount.

\section{Clinical presentation}

Symptoms typical of UP are dysuria, frequency, urgency, hematuria with vaginal bleeding from the friable edematous mucosa being the most common presenting condition. Signs typical of UP are a circumferential lesion/mass of periurethral mucosa that may appear red/purple/pink-it is often described as an "annular rosette." The prolapse may even have the appearance of necrotic or infected tissue around the urethral meatus [103,104]. Although, somewhat similar to a urethral caruncle in physical appearance it can be initially differentiated by the complete circumferential nature of the everted tissue and also caruncles tend to have a brighter red appearance than a UP.

\section{Diagnosis}

A urinary catheter can be placed within the meatus and if the anomalies tissue appears to surround the catheter with the meatus lying at the center of the tissue-along with the aforementioned signs and symptoms. Often, this is sufficient for diagnosis and to initiate treatment.

\section{Management}

Initial treatment is conservative and usually begins with twice daily Sitz baths with topical application of estrogen cream (e.g. Estrace $0.01 \%)$ at the affected area for a 2 -week period. If at the end of the 2 -week period the UP remains but progress towards resolution is seen continuation of this conservative management may proceed. A high recurrence, up to $67 \%$, has been described from the non-operative management [105]. Surgical excision is rarely necessary and often is reserved for necrotic tissue but if it is necessary a "four-quadrant excisional technique" may be utilized with reanastomosis of the mucosal edges. Typically, an indwelling urinary foley will remain in place thereafter for 5-10 days $[103,106]$.

\section{Urethral Diverticulum}

A urethral diverticulum is a rare condition where an outpouching or cavity forms within the periurethral fascia, adjacent to the urethral 
lumen. They occur predominantly in the distal $2 / 3^{\text {rds }}$ of the urethra; but, can occur anywhere along the urethra. Urethral diverticula most commonly affect females in the third to fifth decade of life, and overall incidence is $1-6 \%$ [107]. They are thought to be acquired with age, but there are documented cases in neonates and children [108]. The current doctrine of thought suggests that urethral diverticula originate from the periurethral glands [109]. Recurrent infection, subsequent obstruction, abscess formation and rupture of the infected glands into the urethral lumen are widely accepted as the etiology of this condition [109]. The defect is often an isolated, cystic appendage with a singular connection to the urethral lumen, labeled the ostia or neck. However, there are diverticula that are more anatomically complicated. Partial extension around the urethra has been described and termed the "saddlebag" urethral diverticulum [110]. There have been reported cases of circumferential extension of the diverticulum around the entire urethra [111]. The size of the lesion may vary greatly from a few millimeters to several centimeters and can change with time. Differential diagnosis includes vaginal wall prolapse, periurethral fibrosis, ectopic ureterocele, skene gland abscess, and both benign and malignant vaginal $v s$. urethral neoplasms [112].

\section{Clinical presentation}

The classic presentation of a urethral diverticulum is dysuria, dyspareunia, and post-void dribbling, however, that triad is only present in a third of patients [107]. Symptoms vary, but most commonly include urinary frequency, urgency, irritation, lower urinary tract symptoms, and pain [113-116]. Recurrent urinary tract infections or cystitis is also a common presenting symptom, most likely due to urinary stasis in the diverticulum [114,117]. Other complaints that have been noted include vaginal discharge, hematuria, urinary retention, and urinary incontinence. Patients may also be asymptomatic. Patients will commonly have a characteristic anterior vaginal wall mass, as most diverticula are located on the posterior urethra [118]. The diverticulum is usually soft and can be tender or non tender. Presence of a firm mass should raise suspicion for a calculus or malignancy, which warrants further evaluation. Because many of the symptoms are nonspecific, patients with urethral diverticula are often misdiagnosed and treated for unrelated conditions. One study found that women with urethral diverticulum took 5.2 years from onset of symptoms to diagnosis. These patients saw an average of nine physicians before the definitive diagnosis was established, even though over half of the patients in that series had palpable masses on exam [119].

\section{Diagnosis}

Diagnosis begins with a thorough history and exam. Secondary to the presentation of urethral caruncle frequently presenting with signs and symptoms related to the more common diagnosis of UTI urine dipstick with or without urine microscopy with or without urine culture are usually the first line laboratory tests ordered. The combination of signs, symptoms and abnormal anatomy often leads the next step of evaluation to either flexible or rigid cystoscopy to evaluate for other causes of irritative or obstructive voiding symptoms [120]. Patients with significant voiding dysfunction or incontinence may benefit from an urodynamic study, as it can identify severity of the dysfunction and set a baseline to compare with after repair [121-123].

While ultrasound, voiding cystourethrogram and MRI are all modalities that may be used to evaluate urethral diverticula MRI is deemed the most optimal and "gold-standard" as it allows clear delineation of the soft tissue anatomy that permits both accurate diagnosis and enhanced surgical planning [120]. The T2 weighted imaging on MRI delineates the ostium in approximately $85 \%$ of cases [120]. Double-balloon Positive-Pressure Urethrography (PPU) and voiding cystourethrography were widely used several years ago, but are no longer recommended because they are uncomfortable for the patient and the quality of their images is void-dependent, as diverticula are only visible during the voiding stage of those studies.

\section{Management}

Conservative management is an option for patients without bothersome symptoms. This includes digital decompression after voiding to reduce the mass or periodic needle aspiration [124]. For patients with recurrent urinary tract infections, conservative management with antibiotic prophylaxis can be utilized, but they should also be offered surgical intervention [120]. It is important to note that conservative options do not correct the anatomical abnormality and that if symptoms develop or worsen, patients should be advanced to imaging and discuss the possibility of surgery. There are no guidelines regarding surveillance while patients are undergoing conservative treatment.

Surgical management is recommended for patients with bothersome symptoms, or if a calculus or malignancy is suspected. No studies have been done to compare different surgical management options, but there are a variety of approaches [125]. Different techniques described include transurethral, open, endoscopic unroofing fulguration incision and obliteration and excision with reconstruction [114,120,126-130].

Of the available techniques, surgical excision with appropriate tension-free, multilayered closure is reported as the gold standard with reported success rates as greater than 90\% [120,131-133]. The procedure of choice for most surgeons is transvaginal diverticulectomy, given its definitive nature $[120,126]$. For patients with concomitant incontinence, autologous pubovaginal sling $v s$. synthetic midurethral sling can be considered, but the decision is highly individualized. Reported diverticula recurrence rate after surgical intervention ranges from 1-25\% [117]. Complications include urethrovaginal fistula (1$8 \%)$, stress urinary incontinence (1-6\%), urethral strictures (0-5\%), and recurrent urinary tract infections (7-31\%) [117].

Patients typically leave a Foley catheter in for 1-2 weeks postoperatively, however, if there is excessive dissection of the urethra, a suprapubic tube can be useful. It is common practice to do VCUG 14 days after surgery, and again 1 week later to assess for any extravasation, however there is little data to support this practice.

\section{Urethral Stricture Disease}

Bladder Outlet Obstruction (BOO) is a common disease entity that most often plagues male patients secondary to complications with their prostates. When encountered with female patients overwhelmingly the etiology is subscribed to Pelvic Organ Prolapse (POP). When discussing $\mathrm{BOO}$ as a whole the considerations of etiology is divided into either anatomical or functional causes. In consideration of anatomical causes the characterization is further subdivided into extrinsic, luminal or urethral etiologies [134]. Extrinsic causes include POP and iatrogenic causes such as poorly fitting pessaries and procedures to treat urinary incontinence. Tumors, lodged foreign bodies, ureterocele and bladder stones point to luminal etiologies of BOO. And, urethral strictures, along with urethral fibrosis, caruncles and paraurethral (Skene's) gland cyst would belong to urethral subdivision of BOO. Urethral stricture as an etiology of $\mathrm{BOO}$ is thought to occur at an incidence between $4-13 \%$ and a prevalence of 3-8\% overall [135-138]. Functional etiologies center largely on pelvic floor dysfunction and detrusorsphincter dyssynergia. 
Urethral stricture in and of itself is most notably thought to be secondary to an iatrogenic or traumatic history often found in patients with a history of pelvic fracture, childbirth, prolonged catheterization or status-post repair for urethral diverticulum, incontinence, a fistula or even prior treatments for urethral stricture that may worsen symptoms $[134,139]$. In a recent study the most common causes of urethral stricture in females was found to be prior urethral instrumentation, traumatic catheterization and history of traumatic childbirth [140]. In fact a study found that perhaps up to $88 \%$ of all female urethral strictures may be secondary to an iatrogenic cause [141]. The more rare causes of stricture have been elucidated as fibroepithelial polyps, urethral tuberculosis, lichen sclerosis and even advanced cervical cancer [134,142-144].

\section{Clinical presentation}

The clinical presentation follows in the line of bladder outlet obstruction with symptoms of straining, incomplete voiding, hesitancy and dribbling. It is not uncommon for women to report pain with micturition along with urgency and frequency. The presence of urinary retention exposes affected patients to increased risk of urinary tract infections with or without incontinence $[134,145,146]$. Depending on the severity of disease rare cases reporting urinary retention leading to renal failure, hydronephrosis and pyelonephritis have been described secondary to urethral strictures $[134,147,148]$. Given that a possible etiology of urethral strictures may be trauma, iatrogenic and/ or radiation the presence of any of the aforementioned symptoms in conjunction with a clinical history involving pelvic trauma, urethral/ vaginal/bladder instrumentation and/or radiotherapy to this affected area should raise suspicion to this diagnosis [146].

\section{Diagnosis}

There is currently no widely accepted definition for urethral stricture disease. A 2013 systematic review offered the definition of "A symptomatic, anatomical narrowing of the urethra based on a failure of catheterization, urethral calibration, visual inspection or endoscopy or radiography." [149]. A pelvic exam may reveal lichen stenosis, pelvic organ prolapse, meatal stenosis or periurethral abnormalities as the etiology of the patient's symptoms [145]. The inability to pass a 14 Fr urethral catheter has been accepted as nearly pathognomonic for the presence of a stricture despite no formal definition regarding the normal caliber of the female urethra [145].

\section{Management}

No consensus management strategy currently exists for female urethral strictures and to a large degree surgical management plans often follow to the comfort and/or expertise of the surgeon in performing a particular procedure [145,146]. While more conservative management plans may utilize smaller caliber Clean Intermittent Catheterization (CIC) or indwelling urinary foleys the surgical management consists of dilation techniques, meatoplasty and/ or urethroplasty with or without usage of flaps or grafts $[145,146,150]$.

Although, a trial of internal urethrotomy/urethral dilation is initially warranted in most cases the overall success rates of complete resolution are low and even those numbers are debatable in their presentations. A study evaluating the effectiveness of urethral dilation/ urethrotomy where within most women the urethra was dilated to between $30 \mathrm{Fr}$ to $41 \mathrm{Fr}$ reported a composite success rate of $47 \%$ with a $58 \%$ and $27 \%$ success rate respectively in cases of no previous dilation or previous dilations [149]. However, it was noted that following the procedures it was recommended that the patients perform daily CIC at least once and success rate pertained more towards the need for reoperation opposed to success rates defined more so by the absence of need to perform CIC and no need for further operations [145,151].

Meatoplasty, more specifically via the Heineke-Mikulicz technique, which involves a longitudinal ventral (which vaginally is more apt to say posteriorly) urethral incision able to accommodate a $20 \mathrm{Fr}$ catheter followed by sewing the urethral tissue in a transverse fashion to the vagina, is likely an ill-advised technique if the stricture is greater than $0.5 \mathrm{~cm}$. The concern stems from the likelihood of creating a hypospadiac meatus. Additionally, simple meatomy should be avoided in patients with lichen sclerosis as the disease will negatively affect the restricted meatus [145,152].

The use of vaginal flaps has been described via anatomical origins of the flaps [145]. Anterior vaginal flaps ("Blandy Flap"), lateral vaginal wall flaps ("Orandi Flap") and vestibular flaps ("Montorsi Flap") overall have been reported with success rates ranging from $80-100 \%$ with mean follow up between 15-24 months in the literature [145,153155]. Successful utilization of this technique is largely derived not only in the surgical technique but also in the considerations of co-morbid conditions. More specifically, patients with lichen sclerosis, vaginal atrophy and/or a short/narrow vagina should be offered other surgical management plans as the conditions subject the patient to either surgical failure or exacerbation of current disease state as in the case of a short narrow vagina $[145,146,149,156]$. While the use of anterior and vestibular flaps are able to accommodate larger strictures than meatomy generally treatment of strictures greater than $2 \mathrm{cms}$ or very proximal strictures should be treated with either graft procedures or lateral vaginal flap urethroplasty [145,156].

Free graft urethroplasty may involve grafts of vaginal, labial, buccal or lingual epithelium/mucosa. The overall success rates are high with vaginal graft success rates ranging from $75 \%-100 \%$ with follow up between 15-24 months and oral mucosa graft rates of approximately 94\% [138,145,157-159]. The decision to proceed with a ventral onlay, with or without a Marituas flap, or dorsal onlay often again is secondary to surgeon comfort with the procedure. But, two points of significant consideration should be evaluated if both options are readily able to be performed. If using a ventral onlay there is the disadvantage of a higher risk of urethrovaginal fistula but affords the advantage of a subsequent insertion of a suburethral sling if a Martius flap is used and the need arises in the future $[145,146,149]$. While a dorsal procedure reduces the risk of an urethrovaginal fistula the proximity to the clitoral neurovascular bundle not only increases the risk of intraoperative bleeding but also permanent nerve damage. The advantage to the dorsal approach is that it is the preferred method if a future insertion of a suburethral sling is expected, and/or fibrosis or unhealthy appearance of tissue is visualized in the anterior vagina this method may still be used $[145,146,149]$.

\section{Primary Urethral Carcinoma (and Primary Urethral Melanoma)}

Primary Urethral Carcinoma (PUC) is overall a rare entity comprising less than $1 \%$ of both all overall malignancies and urinary tract malignancies as a subset $[160,161]$. As such, much of the literature discussing the clinical presentation, risk factors, histology, treatment and prognosis is composed primarily of case reports or small series [162-167]. Although, large population based resources such as the European Commission's RARECARE and the National Cancer Institute's Surveillance, Epidemiology and End Results (SEER) program have reported on urethral cancer; the prognostic impact of many tumor characteristics and patient demographics not only remains unclear but often presents with conflicting results [168-171]. A 
central hypothesis to the reason for the conflicting data, demographic prognostic factors, treatment and survival outcomes lies at the very definition of what comprises PUC [172]. Essentially, a tumor found within the urethra is not always a PUC. When considering the urethra as a whole some of the literature reports on tumors within the urethra indiscriminately. Whereas, currently an emerging consensus is that urethral tumors in the in the proximal urethra are frequently secondary tumors extending from the bladder and of urothelial origin. Opposed to tumors located distally at the meatus which may represent tumors extended from the vulva [172]. Understandably, tumors found in the urethra by extension, although they may be comprised of a histologic type found in PUC, possess a prognosis and treatment that differs.

The estimated prevalence of PUC among North American females is 1.5 per million; opposed to males with a 4.3 per million prevalence [169]. The mean age at diagnosis appears to be around 69 years old with a higher incidence in Black patients and initially it was thought also in women $[169,172]$. Although some studies have identified a higher incidence of PUC in women compared to men larger, multiinstitutional studies conflict those findings and are believed to be more representative of actual demographic findings as a whole $[169,170]$.

The World Health Organization (WHO) presented a scheme of PUCs in 2016 where they were classified primarily as urothelial, squamous or adenocarcinomas of enteric type occasionally exhibiting mucinous features or unspecified. Additionally, the extremely rare forms of clear cell and adenoid cystic carcinomas were classified [172, 173]. Of the aforementioned histologic subtypes of urethral cancer the most common three subtypes Urothelial Carcinoma (UC) is found in $30-78 \%$ of cases, Squamous Cell Carcinoma (SCC) is found at $12-29 \%$ of cases and Adenocarcinoma is found in 5-29\% of cases [168-171]. As it pertains to prognostic factors a diagnosis of $\mathrm{AC}$ in women was found to be unfavorable in women while in men it is a more favorable subtype $[168,170]$. Women, in fact have an increased hazard of death when diagnosed with that subtype and somewhat in line with the previously discussed increased incidence amongst Black patients black women were found to have an increased relative incidence rate of AC $[169,170]$. Women diagnosed with PUC have been found to have a median estimated survival of 42 months, opposed to men with a non-statistically significant difference of 48 months, according to SEER data [170]. The median Cancer-Specific-Survival (CSS) time for PUC is approximately 78 months with advanced age, node-positive disease, non-squamous histologic features, black race and Stage T3-T4 disease compared to T1 to be associated with shortened CSS [168]. Black race demonstrates a disparity in survival outcomes; however, when stratified by sex there is not a statistically significant difference in survival. The etiology of the disparity is unclear but tumor biology and access to treatment have been posited as etiologies especially in consideration to the finding that black patients are found to present with a statistically significant greater $\mathrm{T}$ stage $[168,170]$. Risk factors for PUC have been found to be presence of urethral diverticula, sexual activity and chronic irritation with some sources identifying HPV infection as a major contribution to the risks [170,174-176]. 5 and 10 year Kaplan-Meier estimates of overall survival from one study were found to be $46 \%$ and $31 \%$ respectively [170].

Urethral cancer is staged via the $7^{\text {th }}$ edition of the TNM (Tumor, Node, Metastasis) classification system [177,178]. When overall survival is stratified by primary $\mathrm{T}$ stage we find that 5 -year overall survival estimates are $63 \%, 38 \%$ and $29 \%$ for $\leq \mathrm{cT} 1, \mathrm{cT} 2$ and $\geq \mathrm{cT} 3$ respectively [170]. Black patients when compared to non-black patients in a particular study were found to have lower mean overall survival although median follow-up duration was not found to be significant between those cohorts in a large study [170].
Although not discussed further below Primary Urethral Melanoma (PUM) presents with the same clinical presentation, means of diagnosis and treatment options. As PUC is rare, PUM presents as a near subset of that rare disease entity comprising less that $0.1-0.2 \%$ of all melanomas $[179,180]$. The subtle differences appear to be mean age of diagnosis which in the systematic reviews ranged from a mean of 64.7-68 years old, an absence of the risk factor of being black as it pertains to survival and presentation of advanced tumor stage and median survival which was reported at 16 months with 5 -year survival of around $10 \%$ opposed to what is written about PUC below. [179,181]. As a whole the reviews found around 100-150 cases reported in the literature ranging from when reviewed, which reported from an undefined time to as late as 1975, up to 2012 again illustrating the rare nature of this disease and inability to fully describe optimal treatment specific treatment modalities $[179,181]$.

\section{Clinical presentation}

The presentation of PUC is often non-specific and therefore a high-index of suspicion is needed for a timely diagnosis. The median duration of time that women contend with symptoms associated with PUC is approximately 4.5 months on average [174,182]. Symptoms composed of recurrent UTIs, irritative symptoms and spotting account for $>70 \%$ of presenting symptoms in women while $23 \%$ presented with obstructive symptoms and $20 \%$ presented with hematuria in a study evaluating the analysis of treatment for female PUC [182]. In one smaller study just over half of the patients presented with a palpable urethral mass as well [183]. In general, the physical exam should evaluate for masses and the presence or absence of inguinal lymphadenopathy for if PUC is the etiology most often the adenopathy is a sign of metastasis [174].

\section{Diagnosis}

As with just about any medical condition the initial evaluation begins with a thorough history and physical exam. Given the relatively non-specific presentation that PUC can have a high index of suspicion is warranted to initiate the following evaluations that would lead to an accurate diagnosis. Presented with symptoms of hematuria, irritative urinary symptoms and/or recurrent UTIs initial laboratory evaluations are likely to commence with urine cytology. Overall urine cytology has a limited role within PUC as the sensitivity tends to be low ranging from 55\%-59\% [58]. Although, not without some utility as for histological subtypes of SCC and UC the sensitivity was found to be $77 \%$ and $50 \%$ respectively [178]. The question of concern is a potential delay in diagnosis and then treatment by awaiting for cytology rather than moving on to some of the following evaluations.

Diagnostic cystourethroscopy and biopsy often permits evaluation of a urethral tumor in regards to tumor extent, location and its underlying histology [59]. The evaluation should include a thorough examination of the bladder to evaluate the presence or absence of extension from the bladder [59]. "Cold-cup" biopsy of abnormal tissue sites permits the tissue to be retrieved for histologic evaluation without engendering artificial tissue damage [178].

A general consensus is that Magnetic Resonance Imaging (MRI) is the preferred radiologic imaging to assess local and regional tumor extent as well as in terms of overall disease staging [172,178]. With evaluation of regional metastatic disease the focus should center on inguinal and pelvic lymph nodes with MRI preferably and CT acceptable while distant imaging should concentrate on the chest and liver with CT imaging $[172,178]$. CT urography has an application if the urothelium in particular desires to be further evaluated $[178,184]$. 
Besides using the aforementioned $7^{\text {th }}$ edition of the TNM staging system when describing PUC the 2004 WHO grading system is used to differentiate PUC of urothelial histology and PUC of non-urothelial histology. The grading system differentiates the Urothelial PUC into the designation of papillary urothelial neoplasm of low malignant potential into either low grade or high grade with histologic findings being either well-differentiated or poorly differentiated, respectively. The nonurothelial PUCs are graded via a trinomial system G1-G3. The G1 designation is described as well differentiated, G2 as moderately differentiated and G3 as poorly differentiated [178].

\section{Management}

With PUC being such a rare entity in and of itself much of the treatment modalities in the literature are again composed from small case series or inferred treatments from other loco-regional type tumors [174]. The literature discusses treatments via chemotherapy, radiotherapy (both external beam and brachytherapy), chemoradiation and surgical procedures ranging from transurethral resection to pelvic exenteration with en bloc removal of pubis and genitourinary diaphragm with or without lymphadenectomy without an ability to define any standard of care given the paucity of evidence pertaining to any one particular treatment modality $[59,168,171,174,178]$. Distal urethrectomy with frozen section of $2 \mathrm{~cm}$ tumor free margins for small exophytic distal tumors is reported as a successful treatment option in a publication looking at PUC surgical treatment outcomes [59,185]. Given that the female urethra is usually $3-4 \mathrm{~cm}$ in total length achieving that $2 \mathrm{~cm}$ disease free margin is often difficult to accomplish without encountering sequalae of urinary incontinence from disruption of the urethral sphincter. In fact, distal sleeve resection of more than 2 $\mathrm{cm}$ of urethra is associated with a $42 \%$ change of secondary urinary sphincteric weakness and incontinence requiring reconstructive surgical repair [186]. No large-scale studies evaluating the effectiveness of transurethral resection or laser as it pertains to female PUC exists currently.

Despite existing as a rare entity PUC appears to present with an inability to use clinical and/or pathological parameters to reliably predict survival. Thereby, providing an idea that all urethral carcinomas should be considered as universally highly aggressive even if in the early superficially invasive stages [172]. When considering surgical management therefore in order to minimize local recurrence a wide-field surgical approach is believed to be of greatest benefit $[59,174]$. As such, descriptions of pelvic exenteration with or without pelvic and/or inguinal LN dissection, pelvic dissection with en bloc removal of the pubis and genitourinary diaphragm in continuity with or without lymphadenectomy and RT, and radical urethral extirpation have been described as means of surgical management $[59,174]$. In the case of radical urethral extirpation it has been proposed that all of the periurethral soft tissues from the bulbocavernosus muscles be removed both bilaterally and distally up to the pubic symphysis and bladder neck. Posteriorly the anterior vaginal wall should also be removed to achieve the minimized local reoccurrence rates [59]. The role of lymph node resection remains ambiguous as no clear evidence supports prophylactic bilateral inguinal and/or pelvic lymphadenectomy in PUC patients [178]. However, it seems prudent to perform regional lymphadenectomy when presented with clinically enlarged inguinal/ pelvic lymph nodes or invasive tumors $[59,178]$. Overall, nodal control has been described via regional lymph node dissection, radiotherapy or chemotherapy in the literature $[59,178,187,188]$.

Primary Radiotherapy (RT) as the sole method of treatment appears to be associated with poor local disease control and a significant proportion of complications. While much of the data is derived from male PUC the 0-25\% 5-year survival rates described in small series is far from promising if considering to offer the treatment in isolation $[189,190]$. Multimodal therapy with chemoradiation has been reported to be effective with advanced staged tumors as a means of consolidating treatment from a report from MD Anderson Cancer Center [174]. By extrapolating the response to treatment of other regional cancers such as vaginal, cervical or anal and with special consideration of how HPV related squamous cell cancers of those regions respond to treatmentregimens have been devised that show promise for increased survival [174]. They found across all histologic types a response rate of $72 \%$ to the regimens they proposed [174].

\section{References}

1. Deng DY (2020) Disorders of the Female Urethra. In: McAninch JW, Lue TF (eds) Smith and Tanagho's General Urology. 19 ${ }^{\text {th }}$ Edition, McGraw-Hill Education, New York.

2. Marrazzo JM, Holmes KK (2018) Sexually Transmitted Infections: Overview and Clinical Approach. In: Jameson JL, Fauci AS, Kasper DL, Hauser SL, Longo DL, et al. (eds) Harrison's Principles of Internal Medicine. 20 ${ }^{\text {th }}$ Edition, McGraw-Hill Education, New York.

3. Young A, Toncar A, Wray AA (2020) Urethritis. StatPearls, Treasure Island (FL).

4. Handsfield HH (1981) Nongonococcal urethritis. Cutis 27: 268-270.

5. Jamison CD, Coleman JS, Mmeje O (2019) Improving Women's Health and Combatting Sexually Transmitted Infections Through Expedited Partner Therapy. Obstet Gynecol 133: 416-422.

6. Centers for Disease Control and Prevention (2019) Chlamydia. Sexually Transmitted Disease Surveillance 2018.

7. Storme O, Saucedo JT, Garcia-Mora A, Dehesa-Dávila M, Naber KG (2019) Risk factors and predisposing conditions for urinary tract infection. Ther Adv Urol 11: 19-28.

8. Mayo Clinic (2019) Urinary Tract Infections (UTI).

9. Michels TC, Sands JE (2015) Dysuria: Evaluation and Differential Diagnosis in Adults. Am Fam Physician 92: 778-786.

10. Katz MH, Doherty GM (2020) Urology. In: Doherty GM (eds) Current Diagnosis and Treatment: Surgery. $15^{\text {th }}$ edition, McGraw Hill LLC, New York.

11. Satterwhite $\mathrm{CL}$, Torrone $\mathrm{E}$, Meites $\mathrm{E}$, Dunne EF, Mahajan R, et al. (2013) Sexually transmitted infections among US women and men: prevalence and incidence estimates, 2008. Sex Transm Dis 40: 187193.

12. Center for Disease Control and Prevention (2019) Gonorrhea. Sexually Transmitted Disease Surveillance 2018.

13. Center for Disease Control and Prevention (2019) National Profile. Sexually Transmitted Disease Surveillance 2018.

14. Territo H, Ashurst JV (2020) Nongonococcal Urethritis (NGU). StatPearls. Treasure Island (FL).

15. Falk L, Fredlund $H$, Jensen JS (2005) Signs and symptoms of urethritis and cervicitis among women with or without Mycoplasma genitalium or Chlamydia trachomatis infection. Sex Transm Infect 81: 73-78.

16. Judson FN, Ruder MA (1979) Effect of hysterectomy on genital infections. Br J Vener Dis 55: 434-438.

17. García-Kutzbach A, Chacón-Súchite J, García-Ferrer H, Iraheta I (2018) Reactive arthritis: update 2018. Clin Rheumatol 37: 869-874. 
18. Stamm WE, Norrby SR (2001) Urinary tract infections: disease panorama and challenges. J Infect Dis 183: S1-S4.

19. Wagenlehner FM, Naber KG (2000) Hospital-acquired urinary tract infections. J Hosp Infect 46: 171-81.

20. Wood EG, Dillon Jr HC (1981) A prospective study of group B streptococcal bacteriuria in pregnancy. Am J Obstet Gynecol 140: 515-520.

21. Jeena PM, Coovadia HM, Adhikari MA (1996) Bacteriuria in children attending a primary health care clinic: a prospective study of catheter stream urine samples. Ann Trop Paediatr 16: 293-298.

22. Cox CE, Lacy SS, Hinman Jr F (1968) The urethra and its relationship to urinary tract infection. II. The urethral flora of the female with recurrent urinary infection. J Urol 99: 632-638.

23. Cox CE (1966) The urethra and its relationship to urinary tract infection: the flora of the normal female urethra. South Med J 59 621-626.

24. Kunin CM, Evans C, Bartholomew D, Bates DG (2002) The antimicrobial defense mechanism of the female urethra: a reassessment. J Urol 168: 413-419.

25. Hutch JA (1970) The Role of Urethral Mucus in the Bladder Defense Mechanism. J Urol 103: 165-167.

26. Sarier M, Kukul E (2019) Classification of non-gonococcal urethritis: a review. Int Urol Nephrol 51: 901-907.

27. Workowski KA, Bolan GA (2015) Sexually transmitted diseases treatment guidelines, 2015. MMWR Recomm Rep 64: 1-137.

28. Wagenlehner FME, Brockmeyer NH, Discher T, Friese $\mathrm{K}$, Wichelhaus TA (2016) The Presentation, Diagnosis, and Treatment of Sexually Transmitted Infections. Dtsch Arztebl Int 113: 11-22.

29. Fihn SD, Johnson C, Stamm WE (1988) Escherichia coli Urethritis in Women with Symptoms of Acute Urinary Tract Infection. J Infect Dis 157: 196-199.

30. Swartz SL, Kraus SJ, Herrmann KL, Stargel MD, Brown WJ, et al. (1978) Diagnosis and etiology of nongonococcal urethritis. J Infect Dis $138: 445-454$

31. Vaginitis in Nonpregnant Patients: ACOG Practice Bulletin Summary, Number 215. Obstet Gynecol 135: 243-245.

32. Papp JR, Schachter J, Gaydos CA, Van Der Pol B (2014) Recommendations for the Laboratory-Based Detection of Chlamydia trachomatis and Neisseria gonorrhoeae-2014. MMWR Recomm Rep 63: 1-19.

33. Masek BJ, Arora N, Quinn N, Aumakhan B, Holdenet J, et al. (2009) Performance of three nucleic acid amplification tests for detection of Chlamydia trachomatis and Neisseria gonorrhoeae by use of selfcollected vaginal swabs obtained via an Internet-based screening program. J Clin Microbiol 47: 1663-1667.

34. Knox J, Tabrizi SN, Miller P, Petoumenos K, Law M, et al. (2002) Evaluation of self-collected samples in contrast to practitionercollected samples for detection of Chlamydia trachomatis, Neisseria gonorrhoeae, and Trichomonas vaginalis by polymerase chain reaction among women living in remote areas. Sex Transm Dis 29: 647-654.

35. Whiley DM, Tapsall JW, Sloots TP (2006) Nucleic acid amplification testing for Neisseria gonorrhoeae: an ongoing challenge. J Mol Diagn 8: 3-15.

36. Johnson RE, Newhall WJ, Papp JR, Knapp JS, Black CM, et al. (2002) Screening tests to detect Chlamydia trachomatis and Neisseria gonorrhoeae infections--2002. MMWR Recomm Rep 51: 1-38.
37. American Urological Association (2020) Medical Student Curriculum: Adult.

38. Johnson JR, Russo TA (2018) Acute Pyelonephritis in Adults. N Engl J Med 378: 48-59.

39. Deng DY, Tanagho EA (2013) Disorders of the Female Urethra. In: McAninch JW, Lue TF (eds) Smith and Tanagho's General Urology $18^{\text {th }}$ edition, McGraw-Hill Education, New York.

40. Harvard Medical School (2019) Urethritis. Harvard Health Publishing.

41. Center for Disease Control and Prevention (2015) Gonococcal Infections. 2015 Sexually Transmitted Diseases Treatment Guidelines.

42. Jacobs NF, Kraus SJ (1975) Gonococcal and Nongonococcal Urethritis in Men. Ann Intern Med 82: 7-12.

43. Martin DH, Mroczkowski TF, Dalu ZA, McCarty J, Jones RB, et al. (1992) A controlled trial of a single dose of azithromycin for the treatment of chlamydial urethritis and cervicitis. The Azithromycin for Chlamydial Infections Study Group. N Engl J Med 327: 921-925.

44. Center for Disease Control and Prevention (2015) Chlamydial Infections. 2015 Sexually Transmitted Diseases Treatment Guidelines.

45. Schwebke JR, Rompalo A, Taylor S, Seña AC, Martin DH, et al. (2011) Re-Evaluating the Treatment of Nongonococcal Urethritis: Emphasizing Emerging Pathogens-A Randomized Clinical Trial. Clin Infect Dis 52: 163-170.

46. Stekler J, Bachmann L, Brotman RM, Erbelding EJ, Lloyd LV, et al. (2005) Concurrent Sexually Transmitted Infections (STIs) in Sex Partners of Patients with Selected STIs: Implications for PatientDelivered Partner Therapy. Clin Infect Dis 40: 787-793.

47. Center for Disease Control and Prevention (2015) Legal Status of Expedited Partner Therapy (EPT). Sexually Transmitted Diseases (STDs).

48. Portman DJ, Gass MLS (2014) Genitourinary syndrome of menopause: new terminology for vulvovaginal atrophy from the International Society for the Study of Women's Sexual Health and the North American Menopause Society. Maturitas 79: 349-354.

49. Gandhi J, Chen A, Dagur G, Suh Y, Smith N, et al. (2016) Genitourinary syndrome of menopause: an overview of clinical manifestations, pathophysiology, etiology, evaluation, and management. Am J Obstet Gynecol 215: 704-711.

50. Castelo-Branco C, Cancelo MJ, Villero J, Nohales F, Juliá MD (2005) Management of post-menopausal vaginal atrophy and atrophic vaginitis. Maturitas 52: S46-S52.

51. (2014) ACOG Practice Bulletin No. 141: management of menopausal symptoms. Obstet Gynecol 123: 202-216.

52. Chang OH, Paraiso MFR (2019) Revitalizing research in genitourinary syndrome of menopause. Am J Obstet Gynecol 220: 246-248.

53. Portman DJ, Gass ML, Vulvovaginal Atrophy Terminology Consensus Conference (2014) Genitourinary syndrome of menopause: new terminology for vulvovaginal atrophy from the International Society for the Study of Women's Sexual Health and the North American Menopause Society. J Sex Med 11: 2865-2872.

54. Stika CS (2010) Atrophic vaginitis. Dermatol Ther 23: 514-522.

55. Nappi RE, Martini E, Cucinella L, Martella S Tiranini L, et al. (2019) Addressing Vulvovaginal Atrophy (VVA)/Genitourinary Syndrome of Menopause (GSM) for Healthy Aging in Women. Front Endocrinol (Lausanne) 10: 561. 
56. Lev-Sagie A (2015) Vulvar and Vaginal Atrophy: Physiology, Clinical Presentation, and Treatment Considerations. Clin Obstet Gynecol 58: 476-491.

57. Fistarol SK, Itin PH (2013) Diagnosis and treatment of lichen sclerosus: an update. Am J Clin Dermatol 14: 27-47.

58. Touijer AK, Dalbagni G (2004) Role of voided urine cytology in diagnosing primary urethral carcinoma. Urology 63: 33-35.

59. Karnes RJ, Breau RH, Lightner DJ (2010) Surgery for urethral cancer. Urol Clin North Am 37: 445-457.

60. Sturdee DW, Panay N, International Menopause Society Writing (2010) Recommendations for the management of postmenopausal vaginal atrophy. Climacteric 13: 509-522.

61. Bachmann G, Lobo RA, Gut R, Nachtigall L, Notelovitz M (2008) Efficacy of low-dose estradiol vaginal tablets in the treatment of atrophic vaginitis: a randomized controlled trial. Obstet Gynecol 111: $67-76$

62. Administration (2019) UFaD Ospemifene.

63. Administration (2016) UFaD Intrarosa.

64. Administration FaD (2018) Statement from FDA Commissioner Scott Gottlieb, M.D., on efforts to safeguard women's health from deceptive health claims and significant risks related to devices marketed for use in medical procedures for "vaginal rejuvenation".

65. Abrams P, Cardozo L, Fall M, Griffiths D, Rosier P, et al. (2002) The standardisation of terminology of lower urinary tract function: report from the Standardisation Sub-committee of the International Continence Society. Neurourol Urodyn 21: 167-178.

66. Kaur H, Arunkalaivanan AS (2007) Urethral pain syndrome and its management. Obstet Gynecol Surv 62: 348-351.

67. Gurel H, Gurel SA, Atilla MK (1999) Urethral syndrome and associated risk factors related to obstetrics and gynecology. Eur J Obstet Gynecol Reprod Biol 83: 5-7.

68. Parsons CL (2011) The role of a leaky epithelium and potassium in the generation of bladder symptoms in interstitial cystitis/overactive bladder, urethral syndrome, prostatitis and gynaecological chronic pelvic pain. BJU Int 107: 370-375.

69. Cakici OU, Hamidi N, Ürer E, Okulu E, Kayigil O (2018) Efficacy of sertraline and gabapentin in the treatment of urethral pain syndrome: retrospective results of a single institutional cohort. Cent European J Urol 71: 78-83.

70. Ivarsson LB, Lindström BE, Olovsson M, Lindström AK (2019) Treatment of Urethral Pain Syndrome (UPS) in Sweden. PLoSOne 14: e0225404.

71. Phillip H, Okewole I, Chilaka V (2014) Enigma of urethral pain syndrome: why are there so many ascribed etiologies and therapeutic approaches? Int J Urol 21: 544-548.

72. Lindstrom BE, Hellberg D, Lindstrom AK (2016) Urethral instillations of clobetasol propionate and lidocaine: a promising treatment of urethral pain syndrome. Clin Exp Obstet Gynecol 43: 803-807.

73. Chen YL, Ha LF, Cen J, Huang QR, Hou WG, et al. (2005) Comparative observation on therapeutic effects of electroacupuncture and manual acupuncture on female urethral syndrome. Zhongguo Zhen Jiu 25: 425-426.

74. Smith $C P$, Nishiguchi J, Leary MO, Yoshimura N, Chancellor MB (2005) Single-institution experience in 110 patients with botulinum toxin A injection into bladder or urethra. Urology 65: 37-41.
75. Sinha D, Arunkalaivanan A (2006) Urethral syndrome: response to alpha-adrenergic blocking agents. Int Urogynecol J Pelvic Floor Dysfunct 17: 659-660.

76. Pranikoff K, Constantino $\mathrm{G}$ (1998) The use of amitriptyline in patients with urinary frequency and pain. Urology 51: 179-181.

77. Costantini E, Zucchi A, Zingaro MD, Mearini L (2006) Treatment of urethral syndrome: a prospective randomized study with Nd:YAG laser. Urol Int 76: 134-138.

78. Kim KK, Sin DY, Park HW (1993) Urethral Caruncle Occurring in a Young Girl. Journal of Korean Medical Science 8: 160-161.

79. Cimentepe E, Bayrak O, Ünsal A, Koç A, Ataoğlu O, et al. (2006) Urethral adenocarcinoma mimicking urethral caruncle. Int Urogynecol J 17: 96-98.

80. Cheng L, Foster SR, MacLennan GT, Lopez-Beltran A, Zhang S, et al. (2008) Inflammatory myofibroblastic tumors of the genitourinary tract-single entity or continuum? J Urol 180: 1235-1240.

81. Burkland CE (1952) Common lesions of the urethra in women. California medicine 76: 69.

82. Cimentepe E, Bayrak O, Unsal A, Koç A, Ataoğlu O, et al. (2006) Urethral adenocarcinoma mimicking urethral caruncle. Int Urogynecol J Pelvic Floor Dysfunct 17: 96-98.

83. Bansal N, Garg G, Vashist S (2018) Primary malignant melanoma of urethra mimicking as urethral caruncle. BMJ Case Rep.

84. Singh I, Hemal AK (2002) Primary urethral tuberculosis masquerading as a urethral caruncle: a diagnostic curiosity! Int Urol Nephrol 34: 101-103.

85. Murphy WM, Beckwith JB, Farrow GM (1994) Tumors of the kidney, bladder, and related urinary structures. Ame Registry of Pathology.

86. Marshall F, Uson A, Melicow M (1960) Neoplasma and caruncles of the female urethra. Surgery, gynecology \& obstetrics 110: 723.

87. Blaivas JG, Flisser AJ, Bleustein CB, Panagopoulos G (2004) Periurethral masses: etiology and diagnosis in a large series of women. Obstet Gynecol 103: 842-847.

88. Neilson D, Grant JF, Smith CT (1989) Squamous intra-epithelial neoplasia presenting as a urethral caruncle. Br J urol (Print) 64: 200201.

89. Rovner ES (2007) Bladder and urethral diverticula. Campbell-Walsh Urology 9: 361-372.

90. Becker LE (1975) Urethral caruncle: a herald lesion for distal urethral stenosis? J Natl Med Assoc 67: 228.

91. Çoban S, Bıyık I (2014) Urethral caruncle: Case report of a rare acute urinary retension cause. Can Urol Assoc J 8: E270.

92. Dolan M, Hill C, Valea F (2017) Benign gynecologic lesions: vulva, vagina, cervix, uterus, oviduct, ovary, ultrasound imaging of pelvic structures. Comprehensive Gynecology. $7^{\text {th }}$ ed. Philadelphia, PA, Elsevier 370-422.

93. Conces MR, Williamson SR, Montironi R, Lopez-Beltran A, Scarpelli $M$, et al. (2012) Urethral caruncle: clinicopathologic features of 41 cases. Human pathology 43: 1400-1404.

94. Bostwick DG, Cheng L (2008) Urologic surgical pathology. Elsevier Health Sciences.

95. Venyo AK (2012) Urethral caruncles: a review of the literature. Webmed Central Urol 3.

96. Verma V, Pradhan A (2020) Management of urethral caruncle-A systematic review of the current literature. Eur J Obstet Gynecol Reprod Biol. 
97. Park DS, Cho TW (2004) Simple solution for urethral caruncle. J urol 172: $1884-1885$

98. Trotman MD, Brewster EM (1993) Prolapse of the urethral mucosa in prepubertal West Indian girls. Br J Urol 72: 503-505.

99. Lowe FC, Hill GS, Jeffs RD, Brendler CB (1986) Urethral prolapse in children: insights into etiology and management. J Urol 135: 100103

100. Kumar D, Kaufman MR, Dmochowski RR (2011) Case reports: periurethral bulking agents and presumed urethral diverticula. Int Urogynecol J 22: 1039-1043.

101. Ko EY, Williams BF, Petrou SP (2007) Bulking agent induced early urethral prolapse after distal urethrectomy. Int Urogynecol J Pelvic Floor Dysfunct 18: 1511-1513.

102. Ghoniem GM, Khater U (2006) Urethral prolapse after durasphere injection. Int Urogynecol J Pelvic Floor Dysfunct 17: 297-298.

103. Klein I, Dekel Y, Stein A (2014) Spontaneous postmenopausal urethral prolapse treated surgically and successfully. Case Rep Urol 2014: 695471.

104. Lobo RA, Gershenson DM, Lentz GM, Valea FA (2016) Comprehensive gynecology. $7^{\text {th }}$ Edition, Elsevier Health Sciences.

105. Jerkins, GR, Verheeck K, Noe HN (1984) Treatment of girls with urethral prolapse. J Urol 132: 732-733.

106. Kliegman RM, St. Geme J (2019) Nelson textbook of pediatrics. $21^{\text {th }}$ Edition, Elsevier Health Sciences.

107. Rovner ES (2008) Urethral diverticula. In: Female Urology. Elsevier $825-844$.

108. Glassman TA, Weinerth JL, Glenn JF (1975) Neonatal female urethral diverticulum. Urology 5: 249-251.

109. Pincus JB, Laudano M, Leegant A, Downing K (2019) Female Urethral Diverticula: Diagnosis, Pathology, and Surgical Outcomes at an Academic, Urban Medical Center. Urology 128: 42-46.

110. Vakili B, Wai C, Nihira M (2003) Anterior urethral diverticulum in the female: diagnosis and surgical approach. Obstet Gynecol 102: 11791183.

111. Rovner ES, Wein AJ (2003) Diagnosis and reconstruction of the dorsal or circumferential urethral diverticulum. J Urol170: 82-86.

112. Dmochowski RR, Ganabathi K, Zimmern PE, Leach GE (1994) Benign female periurethral masses. J Urol 152: 1943-1951.

113. Davis HJ, Telinde RW (1958) Urethral diverticula: an assay of 121 cases. J Urol 80: 34-39.

114. Davis BL, Robinson DG (1970) Diverticula of the female urethra: assay of 120 cases. J Urol 104: 850-853.

115. Leach G, et al. (1986) Surgical treatment of female urethral diverticulum. In: Seminars in urology.

116. Peters $3^{\text {rd }}$ W, Vaughan ED Jr (1976) Urethral diverticulum in the female. Etiologic Factors and Postoperative Results. Obstet Gynecol47: 549-552.

117. Ganabathi K, Leach GE, Zimmern PE, Dmochowski R (1994) Experience with the Management of Urethral Diverticulum in 63 Women. J Urol 152: 1445-1452.

118. Aspera AM, Rackley RR, Vasavada SP (2002) Contemporary evaluation and management of the female urethral diverticulum. Urol Clin North Am 29: 617-624.
119. Romanzi LJ, Groutz A, Blaivas JG (2000) Urethral diverticulum in women: diverse presentations resulting in diagnostic delay and mismanagement. J Urol 164: 428-433.

120. Greiman AK, Rolef J, Rovner ES (2019) Urethral diverticulum: A systematic review. Arab J Urol 17: 49-57.

121. Reid RE, Gill B, Laor E, Tolia BM, Freed SZ, et al. (1986) Role of urodynamics in management of urethral diverticulum in females. Urology 28: 342-346.

122. Summitt Jr RL, Stovall TG (1992) Urethral diverticula: evaluation by urethral pressure profilometry, cystourethroscopy, and the voiding cystourethrogram. Obstet Gynecol 80: 695-699.

123. Bhatia NN, McCarthy TA, Ostergard DR (1981) Urethral pressure profiles of women with urethral diverticula. Obstet Gynecol 58: 375378.

124. Fortunato P, Schettini M, Gallucci M (2001) Diagnosis and therapy of the female urethral diverticula. Int Urogynecol J Pelvic Floor Dysfunct 12: 51-57.

125. Bodner-Adler B, Halpern K, Hanzal E (2016) Surgical management of urethral diverticula in women: a systematic review. Int Urogynecol J 27: 993-1001.

126. Spence HM, Duckett JW Jr (1970) Diverticulum of the female urethra: clinical aspects and presentation of a simple operative technique for cure. J urol 104: 432-437.

127. Roehrborn C (1988) Long term follow-up study of the marsupialization technique for urethral diverticula in women. Surg Gynecol Obstet 167: 191-196.

128. Spencer WF, Streem SB (1987) Diverticulum of the female urethral roof managed endoscopically. J urol 138: 147-148.

129. Saito S (2000) Usefulness of diagnosis by the urethroscopy under anesthesia and effect of transurethral electrocoagulation in symptomatic female urethral diverticula. J endourology 14: 455457

130. Ellik M (1957) Diverticulum of the female urethra: a new method of ablation. J urol 77: 243-246.

131. Ljungqvist $L$, Peeker R, Fall M (2007) Female urethral diverticulum: 26-year followup of a large series. J Urol 177: 219-224.

132. Nickles SW, Ikwuezunma G, MacLachlan L, El-Zawahry A, Rames R et al. (2014) Simple vs. complex urethral diverticulum: presentation and outcomes. Urol 84: 1516-1519.

133. Ingber MS, Firoozi F, Vasavada SP, Ching CB, Goldman HB, et al. (2011) Surgically corrected urethral diverticula: long-term voiding dysfunction and reoperation rates. Urology 77: 65-69.

134. Keegan KA, Nanigian DK, Stone AR (2008) Female urethral stricture disease. Curr Urol Rep 9: 419-423.

135. Carr LK, Webster GD (1996) Bladder outlet obstruction in women. Urol Clin North Am 23: 385-391.

136. Groutz A, Blaivas JG, Chaikin DC (2000) Bladder outlet obstruction in women: definition and characteristics. Neurourol Urodyn 19: 213 220.

137. Kuo HC (2005) Videourodynamic characteristics and lower urinary tract symptoms of female bladder outlet obstruction. Urology 66: 1005-1009.

138. Osman NI, Chapple CR (2015) Contemporary surgical management of female urethral stricture disease. Curr Opin Urol 25: 341-345. 
139. Agochukwu-Mmonu N, Srirangapatanam S, Cohen A, Breyer B (2019) Female Urethral Strictures: Review of Diagnosis, Etiology, and Management. Curr Urol Rep 20: 74.

140. Spilotros M, Malde S, Solomon E, Grewal M, Mukhtar BM, et al. (2017) Female urethral stricture: a contemporary series. World J Urol 35: 991-995.

141. Anast J, Brandes SB, Klutke C (2008) Female Urethral Reconstruction. In: Brandes SB (eds) Urethral Reconstructive Surgery. Humana Press 303-314.

142. Pugliese JM, Morey AF, Peterson AC (2007) Lichen sclerosus: review of the literature and current recommendations for management. J Urol 178: 2268-2276.

143. Desai S, Libertino AJ, Zinman L (1973) Primary carcinoma of the female urethra. J Urol 110: 693-695.

144. Indudhara R, Vaidyanathan S, Radotra BD (1992) Urethral tuberculosis. Urol Int 48: 436-438.

145. Waterloos M, Verla W (2019) Female Urethroplasty: A Practical Guide Emphasizing Diagnosis and Surgical Treatment of Female Urethral Stricture Disease. Biomed Res Int 2019: 6715257.

146. Hoag N, Chee J (2017) Surgical management of female urethral strictures. Transl Androl Urol 6: S76-S80.

147. Merimsky E (1985) Retention secondary to urethral stricture in the female. Urology 26: 598.

148. Romero Pérez P, Mira Llinares A (1995) Renal and ureteral complications of urethral stenosis. Actas Urol Esp 19: 432-440.

149. Osman NI, Mangera A, Chapple C (2013) A systematic review of surgical techniques used in the treatment of female urethral stricture. Eur Urol 64: 965-973.

150. Hampson LA, Myers JB, Vanni AJ, Virasoro R, Smith TG $3^{\text {rd }}$, et al. (2019) Dorsal buccal graft urethroplasty in female urethral stricture disease: a multi-center experience. Transl Androl Urol 8: S6-S12.

151. Smith AL, Ferlise VJ, Rovner ES (2006) Female urethral strictures: successful management with long-term clean intermittent catheterization after urethral dilatation. BJU Int 98: 96-99.

152. Stewart L, McCammon K, Metro M, Virasoro R (2014) SIU/ICUD Consultation on Urethral Strictures: Anterior urethra-lichen sclerosus. Urology 83: S27-S30.

153. Önol FF, Antar B, Köse O, Erdem MR, Önol ŞY (2011) Techniques and results of urethroplasty for female urethral strictures: our experience with 17 patients. Urology 77: 1318-1324.

154. Gormley EA (2010) Vaginal flap urethroplasty for female urethral stricture disease. Neurourol Urodyn 29: S42-S45.

155. Simonato A, Varca V, Esposito M, Carmignani G (2010) Vaginal flap urethroplasty for wide female stricture disease. J Urol 184: 13811385.

156. Mukhtar BMB, Spilotros M, Malde S, Greenwell TJ (2017) Ventralonlay buccal mucosa graft substitution urethroplasty for urethral stricture in women. BJU Int 120: 710-716.

157. Önol FF, Önol ŞY, Tahra A, Boylu U (2014) Ventral inlay labia minora graft urethroplasty for the management of female urethral strictures. Urology 83: 460-464.

158. Rehder P, Glodny B, Pichler R, Exeli L, Kerschbaumer A, et al. (2010) Dorsal urethroplasty with labia minora skin graft for female urethral strictures. BJU Int 106: 1211-1214.
159. Gozzi C, Roosen A, Bastian PJ, Karl A, Stief C, et al. (2011) Volar onlay urethroplasty for reconstruction of female urethra in recurrent stricture disease. BJU Int 107: 1964-1966.

160. Gatta G, van der Zwan JM, Casali PG, Siesling S, Dei Tos AP, et al. (2011) Rare cancers are not so rare: the rare cancer burden in Europe. Eur J Cancer 47: 2493-2511.

161. Amin MB, Young RH (1997) Primary carcinomas of the urethra. Semin Diagn Pathol 14: 147-160.

162. Zinman LN, Vanni AJ (2016) Management of Proximal Primary Urethral Cancer: Should Multidisciplinary Therapy be the Gold Standard? Urol Clin North Am 43: 505-513.

163. Yvgenia R, Ben Meir D, Sibi J, Koren R (2016) Mucinous adenocarcinoma of posterior urethra. Report of a case. Pathol Res Pract 201: 137-140.

164. Benson Jr RC, Tunca JC, Buchler DA, Uehling DT (1982) Primary carcinoma of the female urethra. Gynecol Oncol 14: 313-318.

165. Hartman K, Li J, Garg T (2018) Clear cell adenocarcinoma of female urethra: A case report. Urol Case Rep 19: 36-38.

166. Maier U, Dorfinger K, Susani M (1998) Clear cell adenocarcinoma of the female urethra. J Urol 160: 492-493.

167. Thyavihally YB, Wuntkal R, Bakshi G, Uppin S, Tongaonkar HB (2005) Primary carcinoma of the female urethra: single center experience of 18 cases. Jpn J Clin Oncol 35: 84-87.

168. Champ CE, Hegarty SE, Shen X, Mishra MV, Dicker AP, et al. (2012) Prognostic factors and outcomes after definitive treatment of female urethral cancer: a population-based analysis. Urology 80: 374-381.

169. Swartz MA, Porter MP, Lin DW, Weiss NS (2006) Incidence of primary urethral carcinoma in the United States. Urology 68: 1164-1168.

170. Sui W, RoyChoudhury A, Wenske S, Decastro GJ, McKiernan JM, et al. (2017) Outcomes and Prognostic Factors of Primary Urethral Cancer. Urology 100: 180-186.

171. Gakis G, Morgan TM, Efstathiou JA, Keegan KA, Mischinger J, et al. (2016) Prognostic factors and outcomes in primary urethral cancer: results from the international collaboration on primary urethral carcinoma. World J Urol 34: 97-103.

172. Zhang M, Adeniran AJ, Vikram R, Tamboli P, Pettaway C, et al. (2018) Carcinoma of the urethra. Hum Pathol 72: 35-44.

173. Moch H, Cubilla AL, Humphrey PA, Reuter VE, Ulbright TM (2016) The 2016 WHO Classification of Tumours of the Urinary System and Male Genital Organs-Part A: Renal, Penile, and Testicular Tumours. Eur Urol 70: 93-105.

174. Dayyani F, Hoffman K, Eifel P, Guo C, Vikram R, et al. (2014) Management of advanced primary urethral carcinomas. BJU Int 114: 25-31.

175. Wiener JS, Walther PJ (1994) A high association of oncogenic human papillomaviruses with carcinomas of the female urethra: polymerase chain reaction-based analysis of multiple histological types. J Urol 151: 49-53.

176. Wiener JS, Liu ET, Walther PJ (1992) Oncogenic human papillomavirus type 16 is associated with squamous cell cancer of the male urethra. Cancer Res 52: 5018-5023.

177. American Urological Association (2020) What is Urethral Cancer.

178. Gakis G, Witjes JA, Compérat E, Cowan NC, De Santis M, et al. (2013) EAU guidelines on primary urethral carcinoma. Eur Urol 64: 823-830. 
179. Papes D, Altarac S (2013) Melanoma of the female urethra. Med Oncol 30: 329

180. Oliva E, Quinn TR, Amin MB, Eble JN, Epstein JI, et al. (2000) Primary malignant melanoma of the urethra: a clinicopathologic analysis of 15 cases. Comparative Study 24: 785-796.

181. El-Safadi S, Estel R, Mayser P, Muenstedt K (2014) Primary malignant melanoma of the urethra: a systematic analysis of the current literature. Arch Gynecol Obstet 289: 935-943.

182. Dalbagni G, Zhang ZF, Lacombe L, Herr HW (1998) Female urethral carcinoma: an analysis of treatment outcome and a plea for a standardized management strategy. Br J Urol 82: 835-841.

183. Gheiler EL, Tefilli MV, Tiguert R, de Oliveira JG, Pontes JE, et al. (1998) Management of primary urethral cancer. Urology 52: 487-493.

184. Picozzi S, Ricci C, Gaeta M, Ratti D, Macchi A, et al. (2012) Upper urinary tract recurrence following radical cystectomy for bladder cancer: a meta-analysis on 13,185 patients. J Urol 188: 2046-2054.
185. Narayan P, Konety B (1992) Surgical treatment of female urethral carcinoma. Urol Clin North Am 19: 373-382.

186. Dimarco DS, Dimarco CS, Zincke H, Webb MJ, Keeney GL, et al. (2004) Outcome of surgical treatment for primary malignant melanoma of the female urethra. J Urol 171: 765-757.

187. Dayyani F, Pettaway CA, Kamat AM, Munsell MF, Sircar K, et al. (2013) Retrospective analysis of survival outcomes and the role of cisplatin-based chemotherapy in patients with urethral carcinomas referred to medical oncologists. Urol Oncol 31: 1171-1177.

188. Garden AS, Zagars GK, Delclos L (1993) Primary carcinoma of the female urethra. Results of radiation therapy. Cancer 71: 3102-3128.

189. Dalbagni G, Zhang ZF, Lacombe L, Herr HW (1999) Male urethral carcinoma: analysis of treatment outcome. Urology 53: 1126-1132.

190. Bracken RB, Henry R, Ordonez N (1980) Primary carcinoma of the male urethra. South Med J 73: 1003-1005. 